\title{
СОВРЕМЕННЫЕ ИНСТРУМЕНТЫ МАРКЕТИНГОВОГО АНАЛИЗА
}

\author{
Н.В. Шепелев \\ Московский гуманитарный университет
}

\begin{abstract}
Аннотация: В данной статье представлены классификаџия и основные группь инструментов, которые актуальны в настоящее время для проведения маркетингового анализа. Маркетинговый анализ используется для обработки полученной маркетинговой информации $c$ целью принятия управленческих решений.

Ключевые слова: маркетинговый анализ, маркетинговые инструменты, аналитические инструменты
\end{abstract}

\section{MODERN MARKETING ANALYSIS TOOLS}

\author{
N. V. Shepelev \\ Moscow University for the Humanities
}

\begin{abstract}
Marketing analysis is used to process the received marketing information in order to make management decisions. In order to get correct results that can be used in the future, it is important to choose the tools that will be used to analyze the information received. This article presents the classification and main groups of tools that are currently relevant for conducting marketing analysis.
\end{abstract}

Keywords: marketing analysis, marketing tools, analytical tools

В рыночных условиях успех или неудача хозяйствующих субъектов определяется мерой использования в их деятельности принципов маркетинга. Он представляет собой процесс планирования и осуществления разработки, установления цены, продвижения и распределения идей, товаров и услуг для создания ситуаций обмена, которые удовлетворяют цели людей и организаций. С помощью маркетинга происходит нацеленность деятельности предприятий на удовлетворение потребностей потребителей. Понимание его сути позволяет руководству фирм принимать более эффективные квалифицированные решения.

Исходным элементом в управлении маркетинговой деятельностью предприятия является маркетинговый анализ.

Слово «анализ» в переводе с греческого означает «разложение», «расчленение». С научных позиций анализ представляет собой метод исследования, суть которого - в мысленном или практическом расчленении целого на составляющие (Никонова, 2018: 67).

Противоположным анализу является метод синтеза, который предполагает сочетание или составление. Несмотря на их противоположность, указанные методы (анализа и синтеза) являются взаимообусловленными и взаимосвязанными. Этот вывод особенно важен для практической деятельности, связанной с проведением любого анализа.

Важно, что маркетинговый анализ рассматривается как одна из функций 
Научные труды Московского гуманитарного университета

2020 № 6

управления. Кроме этого, в данном определении указывается его целевое направление.

Отечественные экономисты определяют маркетинговый анализ как изучение товаров и услуг, спроса и предложения, поведения потребителей, рыночной конъюнктуры с целью эффективного продвижения товаров (услуг) на рынке (Самсонова, 2017: 114). Однако изучение товаров и услуг, спроса и предложения, поведения потребителей и рыночной конъюнктуры относится к сфере маркетинговых исследований.

Маркетинговый анализ и маркетинговые исследования - это два разных направления (хотя они между собой и связаны) и имеют отдельный изолированный предмет своего изучения.

Проведение исследования научных публикаций позволило сформулировать определение сущности маркетингового анализа:

- маркетинговый анализ имеет дело с оценкой маркетинговой деятельности предприятий за прошлые периоды;

- маркетинговый анализ охватывает не только непосредственно процесс маркетинговой деятельности, но и те факторы, которые могут на него влиять, например, макросреда, в которой действует фирма, конечные результаты маркетинговой деятельности и т.п.;

- маркетинговый анализ по форме тесно связан с другими видами анализа, в частности, анализом производственно-хозяйственной деятельности предприятия, имея при этом свой отдельный предмет изучения (оценки);

- маркетинговый анализ имеет четкую целевую ориентацию - повышение эффективности маркетинговой деятельности фирмы в плановом периоде.

Таким образом, маркетинговый анализ - это одно из направлений аналитической работы предприятия, который предусматривает комплексную оценку его маркетинговой деятельности за истекший период с целью выработки эффективной маркетинговой политики на будущее.

По форме проведения маркетинговый анализ не отличается от других видов анализа (анализа производственной деятельности предприятия, финансового анализа и т.д.). И должен проводиться в любых ситуациях, в которых находится фирма, в частности, при изменении окружающей среды, достижении положительных конечных результатов, при наличии упущений и т.д.

Несмотря на то, что внешняя среда, в которой функционирует фирма, постоянно меняется, значение маркетингового анализа возрастает, его результаты являются важными и нужными при разработке маркетинговых стратегий предприятия. Получаемая в процессе проведения анализа информация, которая касается потребителей, положения данной фирмы на рынке, уровня ее конкурентоспособности, является неоценимой в выработке решений, направленных на улучшение деятельности фирмы, в том числе и маркетинговой. 
Проведение маркетингового анализа является необходимым, независимо от того, достигло ли предприятие запланированной прибыли или нет. Положительные результаты в маркетинговой деятельности являются следствием тех решений, которые были приняты фирмой в прошлом (отчетном) периоде.

В будущем ситуация может меняться, что обуславливает принятие новых маркетинговых решений. Кроме этого, за средними хорошими показателями (объем продаж, прибыль, рентабельность) могут скрываться отдельные просчеты и упущения. Поэтому для всех этих случаев (изменения ситуаций, которые будут иметь место в будущем, выявление упущенных возможностей в прошлом периоде) крайне необходимым является проведение маркетингового анализа.

Реализация метода маркетингового анализа осуществляется с помощью использования значительного количества разнообразных инструментов.

Все инструменты, используемые в системе маркетингового анализа можно разделить на 4 группы: традиционные; детерминированный факторный анализ; статистический факторный анализ; способы оптимизации показателей. Основные инструменты маркетингового анализа и их классификация представлена на рисунке.

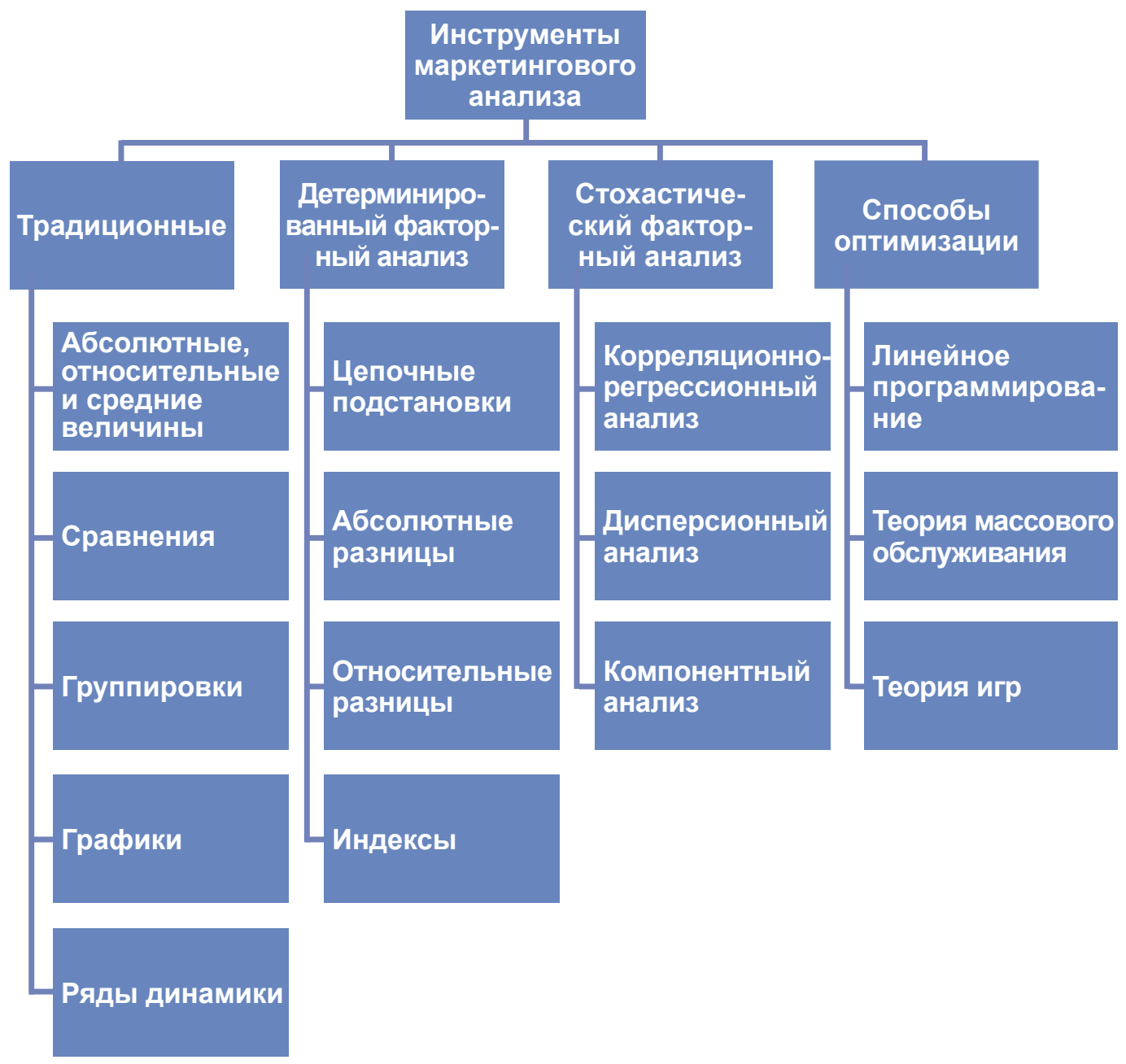

Рис. 1. Инструменты маркетингового анализа 
Научные труды Московского гуманитарного университета

2020 № 6

К первой группе можно отнести такие инструменты, как абсолютные, относительные и средние величины, сравнения, ряды динамики, группировки и графики. Анализ показателей, процессов, ситуаций начинается с использования абсолютных величин (объем продаж, расходы на маркетинг, прибыль и т.д.). Без абсолютных величин в анализе обойтись невозможно. Они являются базой для расчета относительных и средних величин, и могут быть выражены как в натуральном, так и в стоимостном выражениях.

Незаменимы при анализе явлений динамики относительные величины. Они играют роль меры соотношения при сопоставлении двух величин. По форме относительные величины могут выражаться в коэффициентах и процентах и могут быть использованы при расчете структуры покупателей, продажи и тому подобное.

В свою очередь, среди относительных показателей различают показатели выполнения плана, динамики, структуры, интенсивности.

Относительная величина выполнения плана - отношение между фактическим и плановым уровнями, которое обычно выражается в процентах.

Для характеристики изменения показателей за определенный промежуток времени используют относительные величины динамики, которые определяются как отношение величины показателя текущего периода к его уровню в предыдущем (базовом) периоде.

Называются они темпами роста (прироста) и выражаются в процентах или коэффициентах. Относительные величины динамики могут быть базисными, когда каждый уровень динамического ряда сравнивается с базисным годом или цепными, при котором сравнение производится с предыдущим годом.

Относительные величины интенсивности показывают степень развития какого-либо явления в соответствующей среде (доля рынка, лояльность покупателей, количество неосознанных покупок).

Сравнение - наиболее распространенный инструмент маркетингового анализа и анализа в целом. Каждый показатель, используемый для оценки и контроля, имеет значение только в сравнении с другими. Однако обязательным правилом использования приема сравнения является сопоставимость показателей по структуре и условиям их формирования, т.к. сравнивать можно только качественно однородные величины. Обеспечить указанное требование можно через применение средних и относительных показателей, корректирующих коэффициентов, методов пересчета (Чеботарева, 2018: 295).

В практической деятельности все чаще возникают ситуации, когда решение необходимо принимать в условиях неопределенности. В результате возникают конфликтные ситуации, в которых участники ставят разные цели, при этом степень постановки и достижение зависят от способа действий участников, каждый из которых стремится максимизировать меру достижения поставленной цели. В 
данном случае, использование инструментов маркетингового анализа является обязательным, т.к. он позволит получить независимые объективные показатели, которые могут быть использованы в принятии управленческих решений.

\section{СПИСОК ЛИТЕРАТУРЫ}

Никонова Н.В. (2018) Систематизация трактовок «Маркетинговый анализ» // Проблемы Науки. №10 (28). С.67-70.

Самсонова Е.В. (2017) Этапы разработки адаптивной маркетинговой стратегии организации // Известия ВГПУ. №3 (78). С. 101-116.

Чеботарёва С.В. (2018) Статистико-математические методы маркетингового анализа // Проблемы экономики и юридической практики. №1 . С.295-297.

Шепелев Никита Владимирович - обучающийся 3 курса образовательной программы магистратуры по направлению подготовки «Экономика предприятия» Московского гуманитарного университета. Научный руководитель - д.э.н., проф. Меньшикова О.И. Адрес: 111395, Россия, г. Москва, ул. Юности, д. 5. Тел.: 7 (499) 374-74-59. Эл. адрес: kafedra@mosgu.ru

Shepelev Nikita Vladimirovich is a 3rd-year student of the master's degree program in the field of enterprise Economics at the Moscow state University for the Humanities. Scientific supervisor-doctor of Economics, prof. Menshikova O. I. Address: 5 Yunosti str., Moscow, 111395, Russia. Phone: +7 (499) 374-74-59. Email: kafedra@mosgu.ru

\section{Для цитирования:}

Шепелев Н.В. Современные инструменты маркетингового анализа // Научные труды Московского гуманитарного университета. 2020. №6. C. 119-123. DOI: https://www.doi. org/10.17805/trudy.2020.6.21 